\title{
Detection of seepage and monitoring of structural changes in earthen embankments by FO DTS
}

\author{
Filip Čejka ${ }^{3}$, Vojtěch Beneš ${ }^{1}$, Balázs Benei ${ }^{2}$ and Zuzana Boukalová ${ }^{3}$ \\ ${ }^{1}$ G IMPULS Praha spol. s r.o., Prístavní 531/24, 17000 Praha 7, Czechia \\ ${ }^{2}$ Golder Associates (Magyarország) Zrt., Hüvösvölgyi út 54., 1021 Budapest, Hungary \\ ${ }^{3}$ VODNÍ ZDROJE, a.s., Jindřicha Plachty 535/16, 15000 Praha 5, Czechia
}

\begin{abstract}
The aim of this paper is to describe an innovation in the monitoring of performance of earth embankments, namely the use of sensing systems for full-time monitoring of ash pond and irrigation pond seepages. In the past decades, due to IT development and cost reduction, the sensor technology segment and associated measurement and monitoring systems have started to expand rapidly. One of the areas of sensor technology suitable for real-time monitoring of earthen embankments is that of fibre optic distributed temperature sensors (FO DTS). This paper deals with the results of pilot measurements performed within the E!11705 FORMTES project in $2018-2020$, as related to the analysis of the existing FO DTS system installed in the irrigation pond in Spain, and on the new implementation of the FO DTS system in part of the embankment of the ash pond in Hungary, and the use of FO DTS systems for monitoring of potential seepage in above mentioned embankment structures. The evaluated pilot tests together with the desk review were used for the validation and enhancement of the novel methodology to enable its real-life implementation both for the existing embankment structures and the development of detailed designs of new structures of similar nature.
\end{abstract}

\section{Introduction}

The risk for European population originating from possible failure of dams and structures designed for flood control (further referred to as embankments) is widespread throughout Europe. In many countries, the number of small dams (up to $15 \mathrm{~m}$ of height) significantly exceeds the number of the large ones. For instance, in the UK the humble earthen flood embankments are by far the most ubiquitous flood risk management assets along the coast and watercourses as stated by Normandale in (Normandale, 2016).

Diverse sensor types have been used for the monitoring of stability and seepage regime in large dams for decades. In recent years, however, the development in the field of information and communication technologies (ICT) and sensing technologies has facilitated their use for the monitoring of small earth embankments used for water storage and flood control. The use of fibre optic distributed temperature sensors (FO DTS) is regarded as having a great potential in embankment monitoring. In this area, research was conducted by Khan et al. (2010) on the automatic detection of singularities (seepage flows) within a trial embankment using optical time-domain reflectometry. In a laboratory experiment, Su and Kang (2013) dealt with seepage detection including the evaluation of seepage intensity based on double-line and single-line heat source data analysis.

Experimental application of FO DTS on real dams is reported, among others, by Pyayt et al. (2014) in the project FP7 UrbanFlood including dams on the Rhine (Germany) and in Boston (UK). On the Rhine dam, real seepage flows were monitored using the FO DTS systems. Research teams from AGH University of Science and Technology in Cracow are dealing with further installations and data evaluations from FO DTS systems on a research polygon (Dwornik, et al., 2016) (Balisa, et al., 2016).

The authors of this paper already investigated the potential of the FO DTS system in monitoring of the seepage condition in an earth embankment within the R\&D project Short Term Assessment and Mitigation of Flood Risks At River Basin Level (E!8688 STAMFOR), implemented between 2014 - 2017. The STAMFOR methodology as presented in (Čejka, et al., 2018) was verified and validated within the follow-up project Flood Risk Management Governance through a systematic approach from technical, organizational and socioeconomic aspects (FORMTES) implemented between $2017-2021$.

While the FORMTES project was focused on many diverse aspects of flood risk management, the pilot phase

\footnotetext{
${ }^{a}$ Corresponding author: zuzana.boukalova@vodnizdroje.cz

DOI 10.3311/FLOODRisk2020.9.3
} 
provided substantial data from two in-situ FO DTS installations, which further enhanced our understanding of the thermal phenomena occurring in earthen embankments affected by active seepages.

In 2017, Schenato published a comprehensive review of the use of FO DTS systems for the monitoring of soil embankments throughout history (Schenato, 2017). This review provided valuable input for the implementation of FO DTS especially at pilot site Hungary. However, it has to be noted that the primary aim of the FORMTES research team was not only to evaluate the potential of FO DTS systems for the monitoring of embankment seepage conditions (a task, which by now has been successfully accomplished many times) but, more specifically, to underpin the installation design process of the FO DTS system by other investigation and survey techniques as defined in the STAMFOR methodology in order to create a robust and reliable monitoring system based on expert knowledge of a particular site of interest.

The STAMFOR methodology describes all the steps needed for a successful implementation of the FO DTS monitoring system. These steps include especially the operations associated with the site reconnaissance survey, the design of the sensing system distribution pattern, and the installation and setting of the system. The entire methodology is divided into the following sequence:

I. Research of available data sources includes the collection and analysis of available information on the area of interest.

II. Indirect survey is used to locate the reference and/or anomalous areas that are suitable for longterm monitoring by the STAMFOR technology. It provides data for a preliminary description of the embankment body as well as for a preliminary location of the monitoring profiles. Within the STAMFOR methodology, the indirect survey methods include a geophysical investigation to locate the reference as well as anomalous embankment sections that are suitable or practical for long-term monitoring. A convenient investigation method is the application of the Geophysical Monitoring System (GMS) according to Boukalová \& Beneš (2007) and Boukalová, et al. (2010)

III. Direct survey using boreholes and pits provides detailed information particularly on the vertical structure of the embankment body in the reference and/or anomalous areas located in the previous step.

IV. Final interpretation and design provides information for precise positioning of the sensing technology in the embankment body based on expert multidisciplinary assessment and calculations of the embankment body model.

V. Implementation stage comprises all the operations necessary for effective installation of the selected sensing technology, further for launching the pilot and, after the calibration is done, the full operation stage of the system.

\section{Pilot sites}

In order to verify the STAMFOR methodology, two sites with significantly different conditions have been selected for pilot testing (Figure 1). This chapter provides a detailed description of both pilot sites and outlines the activities carried out at these sites within the FORMTES project. Complying with the request by the facility owners, the names and exact locations of the pilot sites will not be disclosed.

The first pilot site is an irrigation pond in southern Spain (PS Spain). The FO DTS system was installed at this site during the construction in 2008 and the main aim of FORMTES was to evaluate the correlation of the geophysical and FO DTS data as well as to assess the FO DTS monitoring potential.

The second pilot site is an ash pond of a decommissioned power plant in NW Hungary (PS Hungary). The FO DTS system was designed and implemented at this site following the STAMFOR methodology in order to verify its field applicability.

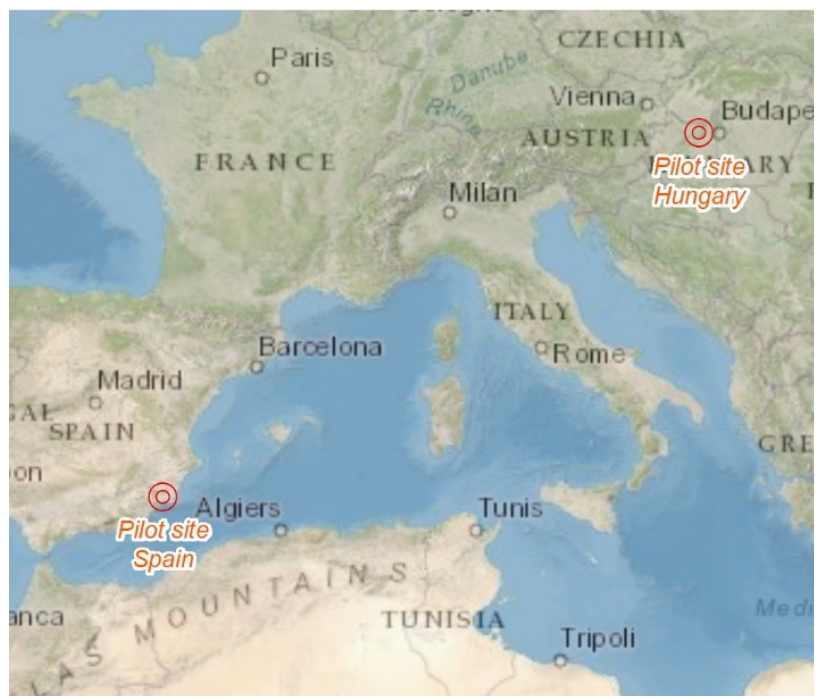

Figure 1. Location of the FORMTES pilot sites

\subsection{PS Spain - irrigation water pond}

The irrigation water pond was constructed in 2008 as one of the main retention ponds for irrigation water. The pond is of rectangular shape with crest dimensions $355 \mathrm{x}$ 310 meters; maximal depth is 13 meters from the crest elevation (276.15 $\mathrm{m}$ a.s.1.). Normal water level elevation is $275.0 \mathrm{~m}$ a.s.l. providing a retention capacity of more than $10^{6}$ cubic meters. Aerial image of the pond is shown in Figure 5 .

Based on the information received from the pond manager, the FO DTS system was installed during the construction of the pond in 2008. Two FO cable layouts were installed, one encircling the waterside toe and the other the waterside berm of the embankment. The only installation design drawing available is shown in Figure 2. No additional information about the depth of the FO cables below the surface has been provided. 


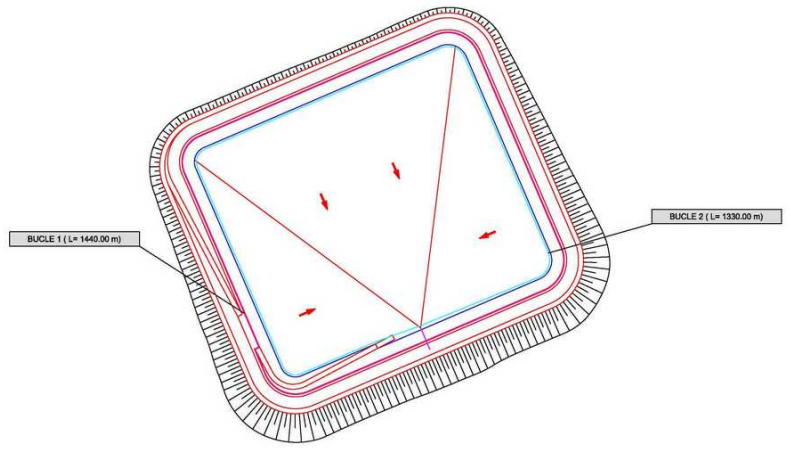

Figure 2. FO DTS layouts as provided by the pond designer

The FO DTS system is operated by the DiTemp ${ }^{\circledR}$ reading unit supplied by the Swiss company SMARTEC SA. This system allows recording of the average temperature of consecutive $2 \mathrm{~m}$ long segments of the optical fibre by using Raman-based optical time domain reflectometry. (SMARTEC, 2018).

The declared aim of the FO DTS system being installed at this site was to provide means for monitoring of the potential seepages through the body of the embankment. However, after a couple of months the system was found dispensable and switched off.

\subsubsection{Site surveys}

In August 2018, a team of experts from VODNÍ ZDROJE, a.s. and G IMPULS Praha spol. s r.o. performed an initial site survey at PS Spain. The survey was intended to provide (1) indirect survey data as stated in step II of the STAMFOR methodology and (2) inspect and recalibrate the on-site FO DTS system. During the survey, the pond was almost empty, only the pond area close to the outflow (middle of the southern embankment) was covered by up to $0.75 \mathrm{~m}$ of water.

The indirect survey methods comprised rapid testing measurement by dipole electromagnetic profiling (Slingram), followed by detailed measurement by electric resistivity tomography (ERT) and spontaneous polarization (SP), as defined in the Geophysical Monitoring System methodology (Boukalová \& Beneš, 2007). This geophysical investigation was performed mainly to obtain some information about the structural composition and potential inhomogeneities and also to acquire an independent reference dataset to be used for a comparative analysis with the expected FO DTS data.

After the inspection of the FO DTS reading unit and several maintenance measures, the FO DTS system was launched. The spatial calibration of the system had to be performed afterwards in order to gather the missing spatial data on the fibre optic layout. The calibration itself comprised 2 phases, namely the use of induced (artificial) temperature anomaly (ITA) and apparent (existing) temperature anomaly (ATA) methods. ITA methods were applied in order to link the known topographic position of the ITA with the internal FO cable chainage of the induced temperature anomaly recorded by the reading unit, while ATA methods were used for refinement of the calibration by linking the known spatial parameters of the installed FO cable.

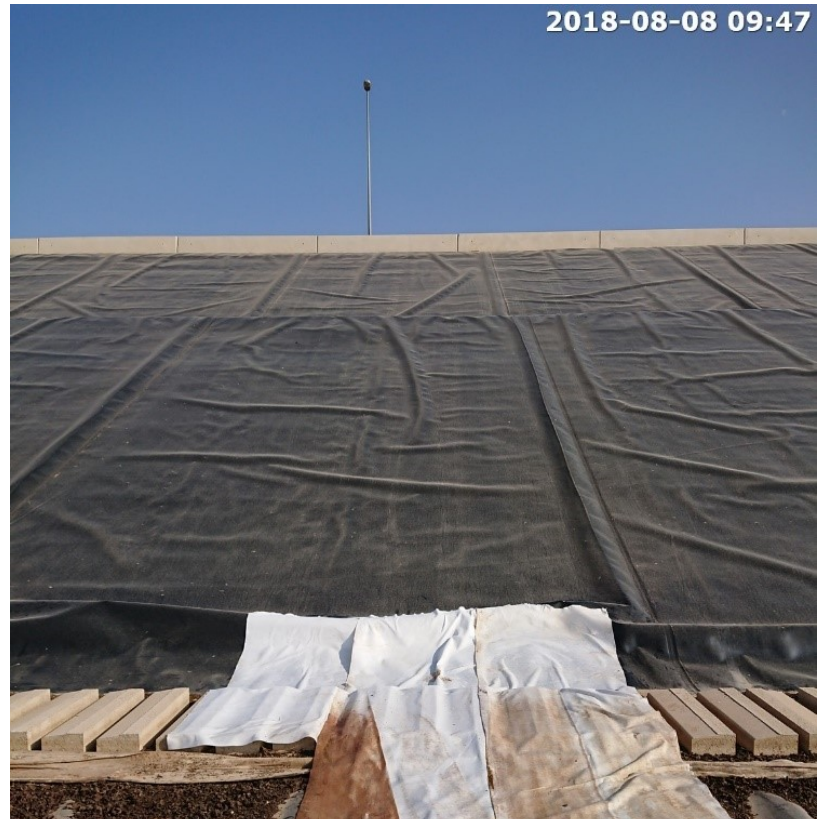

Figure 3. Sunscreen ITA with EXIF time of execution

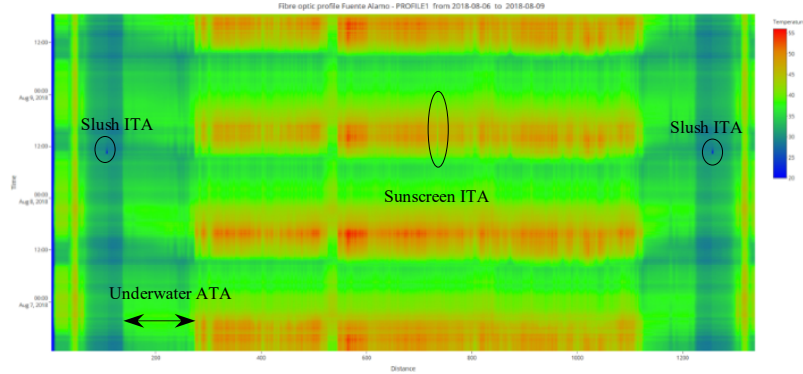

Figure 4. FO DTS time series heatmap of the Layout 1 with ITA and ATA anomalies

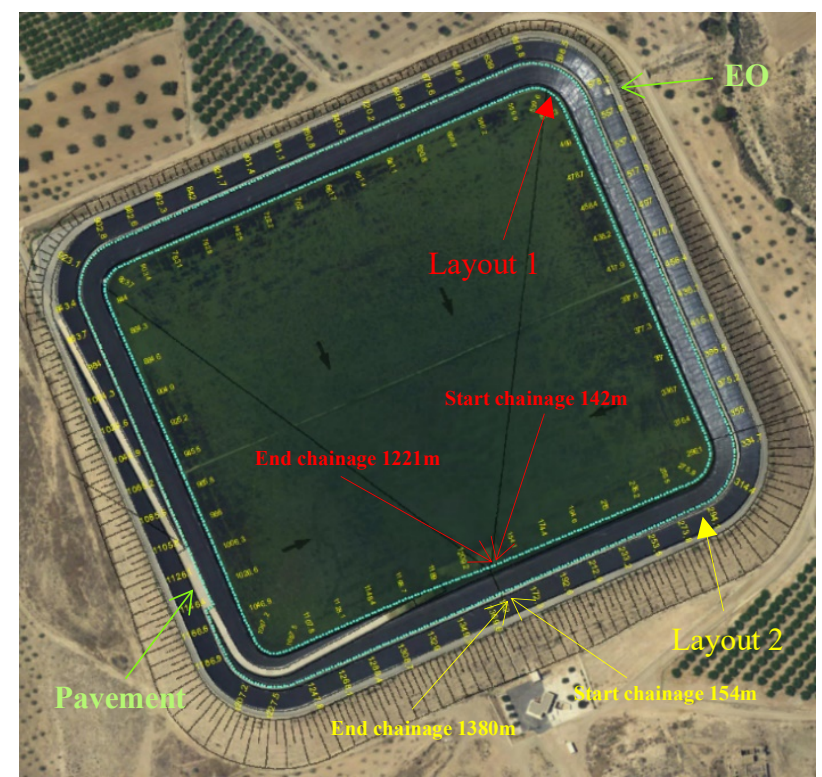

Figure 5. FO cable layouts identified at PS Spain

The first ITA (called Sunscreen) was created by covering the black HDPE sealing foil with white geotextile stripes in an area where the FO cable was estimated to have been installed, hence causing a significant temperature 
drop of the covered section (Figure 3). As the Sunscreen ITA was executed at a specific time, it was also possible to indirectly evaluate the approximate depth of the FO cable installation based on the delay between the time of the ITA execution and the time of the response recorded by the FO DTS unit.

The second ITA (called Slush) was achieved by covering a particular section of the FO cable by ice slush. As the cable layouts had been installed in loops encircling the embankment toe and berm, respectively, and as the slush anomaly covered both ends of each layout loop, the Slush ITA provided relatively precise identification of the active measurement parts of both layouts.

Based on the heat map and GIS analysis of the abovementioned methods (Figure 4), the FO cable chainage of the measurement sections were identified with sufficient precision (Figure 5). The pilot measurement at PS Spain was performed in several periods of 2018 and 2019 (see details in chapter 3.1 below).

\subsection{PS Hungary - coal power plant ash pond}

The second pilot site is the embankment of an ash pond of a former coal power plant. The site is located in north western Hungary near a coal mining town. The ash pond is located north of a cooling pond, which was constructed by damming a watercourse (Figure 6).

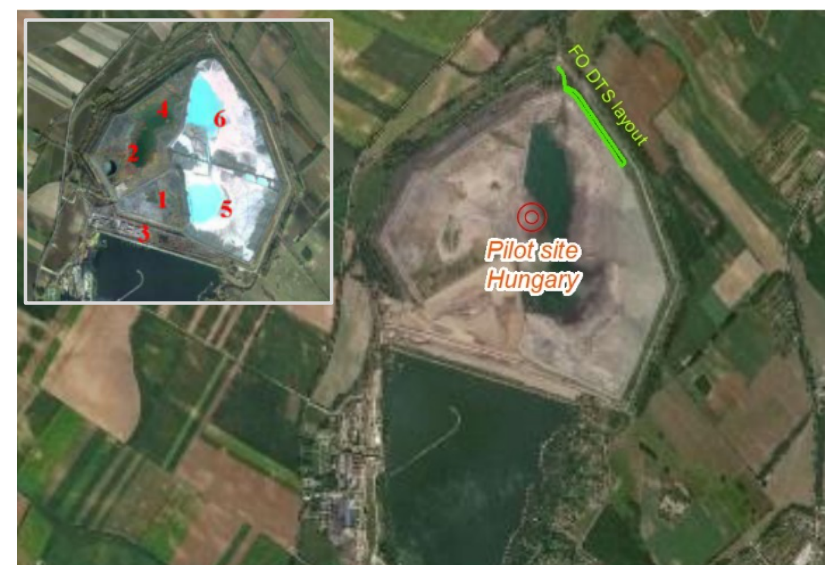

Figure 6. Ash pond and cooling pond in Hungary (Sections of the ash pond outlined)

While the ash pond is recently not being used for its original purpose, it has become subject to many research, survey, and monitoring activities. These include, among others, inclinometric measurements, water amount determination, geophysical survey, seismographic survey, geodetic control points, and water level monitoring. The results of these investigations provided valuable information about the dam body.

\subsubsection{Site surveys and installation}

The first geophysical survey took place in June 2018. By using the Slingram method followed by the detailed ERT and SP methods, several weak zones with potential shallow seepages were identified (turquoise ovals in Figure 7 accompanied by ERT charts). Based on the results of this survey, the preliminary FO DTS layout was

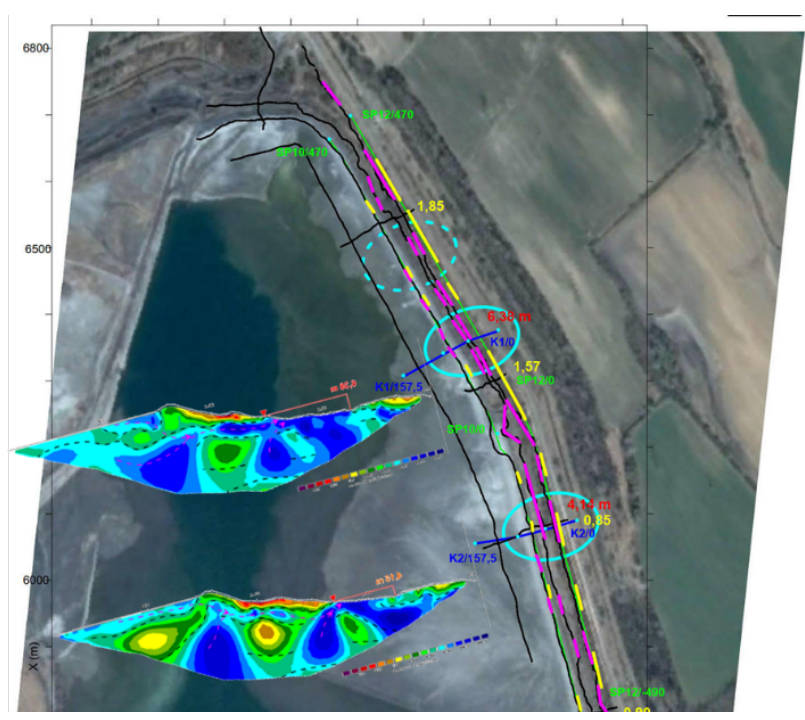

Figure 7. Evaluation of the geophysical survey with assumed seepages, weak zones (torquois) and ERT sections

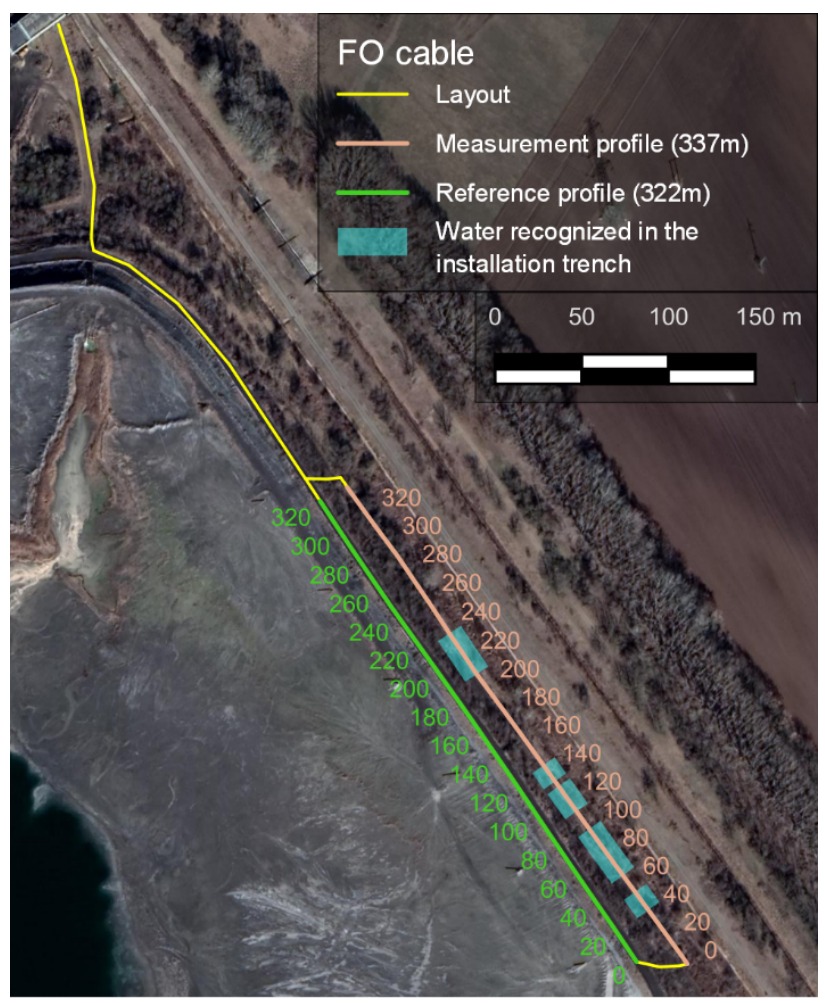

Figure 8. FO DTS layout with measurement and reference profile; water in trench indicated

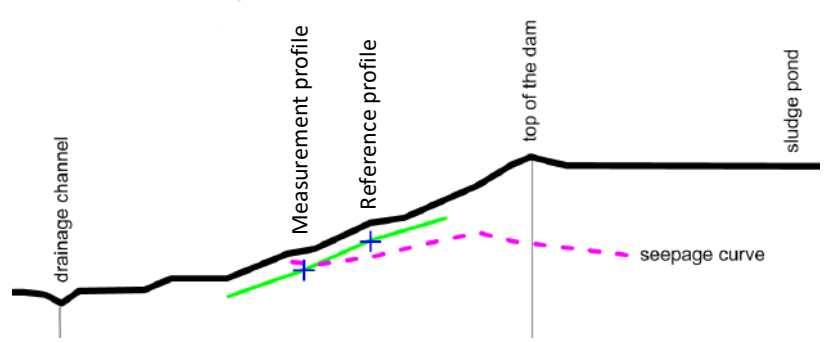

Figure 9. Cross section of the pond embankment indicating the position of the measurement and reference sections in relation to the seepage curve 
designed and eventually installed as indicated in Figure 8. The layout was set to follow the loop with both ends attached to the reading unit in the pumping station located at the northern corner of the pond. The FO cable layout was designed to provide a $337 \mathrm{~m}$-long measurement profile along the bottom part of the landside slope crossing the expected shallow seepage zones, and a 322m-long reference profile along the upper part of the landside slope to provide data without any apparent effect of the seeping water (Figure 9).

The FO DTS installation took place in 2019 from $29^{\text {th }}$ November to $2^{\text {nd }}$ December. The work consisted of 3 activities:

- monitoring geophysical measurement that aimed to verify and specify the presence of anomalies interpreted in 2019 and determine changes in the dam body that may have taken place over a year's time

- installation of $1400 \mathrm{~m}$ of optical fibre cable OX1ECH 01.04.M2.B into pre-arranged trenches and geodetic surveying of the positions of the optical cables as well as surveying of points for the FO DTS system calibration

- start of FO DTS system ITA calibration and measurement

\section{Data gathering and evaluation}

\subsection{PS Spain}

The measurement at PS Spain took place in three seasonal campaigns.

The first campaign was organized between $6^{\text {th }}$ and $29^{\text {th }}$ August 2018. The beginning of the campaign $\left(6^{\text {th }}-8^{\text {th }}\right.$ of August) provided the FO DTS setup and calibration data (as stated in chapter 2.1.1), while the main aim of the rest of the campaign was to provide a longer dataset of temperature changes of an empty pond.

The second campaign took place in March 2019 aiming to collect temperature data for the period when the pond was full.

The third campaign was organized in the summer and autumn 2019 in order to collect the "full pond" data also during the maximal heat intensity. However, on $20^{\text {th }}$ of May 2019 the local technical issues forced the manager to discharge the pond relatively quickly. This coincidence allowed the team to also record the changes of the FO DTS data during a significant water drop.

\subsubsection{Campaign 1}

The data from the first campaign already provided the team with a lot of evidence that the FO cables had been installed close below the HDPE insulation foil. This fact can be clearly seen from the immediate response of the FO DTS to the Sunscreen ITA (see time of the anomaly start in the chart in Figure $\mathbf{1 0}$ and EXIF timestamp in Figure 3).

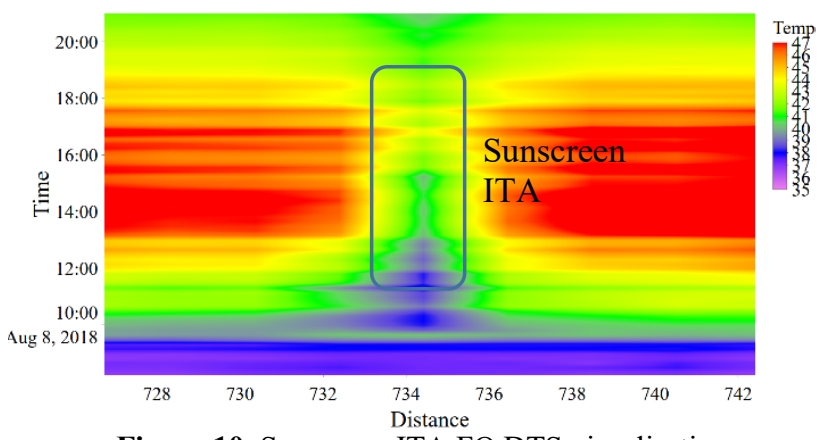

Figure 10. Sunscreen ITA FO DTS visualisation

The above-mentioned shallow installation setup is also apparent from other measured data both from Layout 1 and 2. For example, anomaly 1a as marked in Figure 11 seems to be caused by a local deeper installation of the FO cable. This section displays similar temperature behaviour as the section of the pavement ATA at Layout 2, i.e. the section, where the FO cable runs below the concrete pavement in the western pond bank (for further reference see Figure 4, Figure 12 and Figure 13). It is clear that the cover layer above the FO cable causes the diurnal amplitude of the temperature cycles to flatten and the temperature extrema to shift into the future.

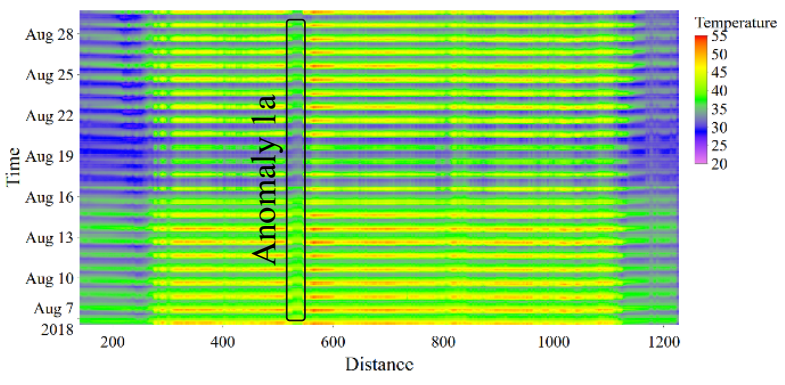

Figure 11. FO DTS Layout 1 - campaign 1

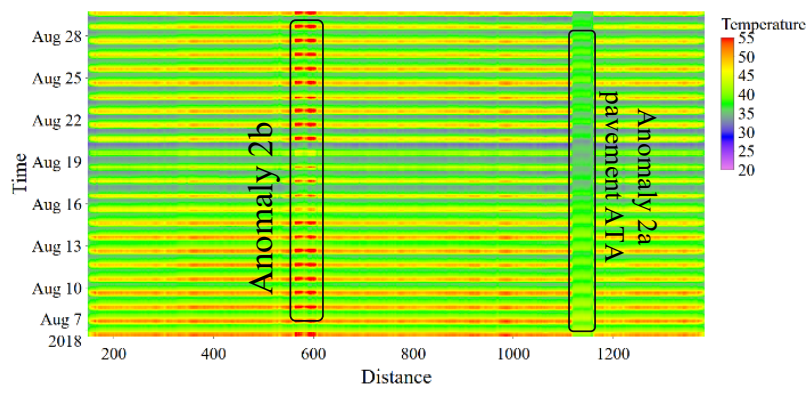

Figure 12. FO DTS Layout 2 - campaign 1

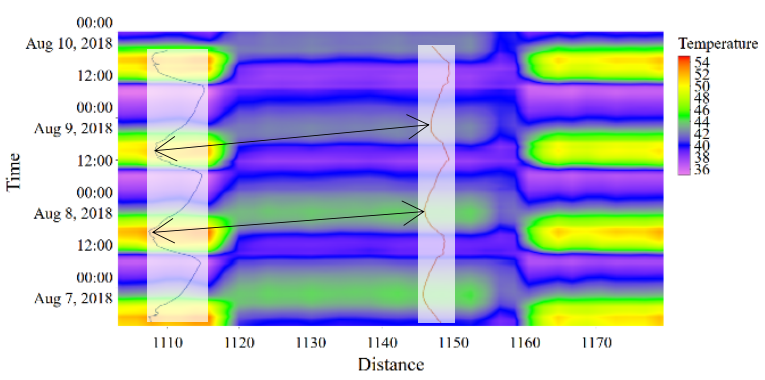

Figure 13. Detail of the pavement ATA with amplitude flattening and extrema timeshift 


\subsubsection{Campaign 2}

During campaign 2 - while the pond was almost full both layouts were covered by a significant water column. Layout 1 is apparently recording only the changes of the water temperature, while Layout 2, being closer to the sun (according to the water level logs from this time the water level was approx. $1-3$ meters above Layout 2) still responds to the sun exposure, as dimmed diurnal temperature cycles are visible in the data.

However, a more interesting phenomenon appears at Layout 2 as anomaly 2b (Figure 12, Figure 14). This anomaly is sharply delimited both spatially and temporally. Since the spatial occurrence of the anomaly nicely matches the emergency overflow structure (see EO in Figure 5), it seems likely that it can be linked to some EO-related structure in the embankment. From the temporal dependency and the fact that the anomaly occurs only at daytime, while at night the data seems to be undistinguishable from the surrounding sections, it seems most likely that a significant thermal bridge transfers the heat into close vicinity of the Layout 2 FO cable.

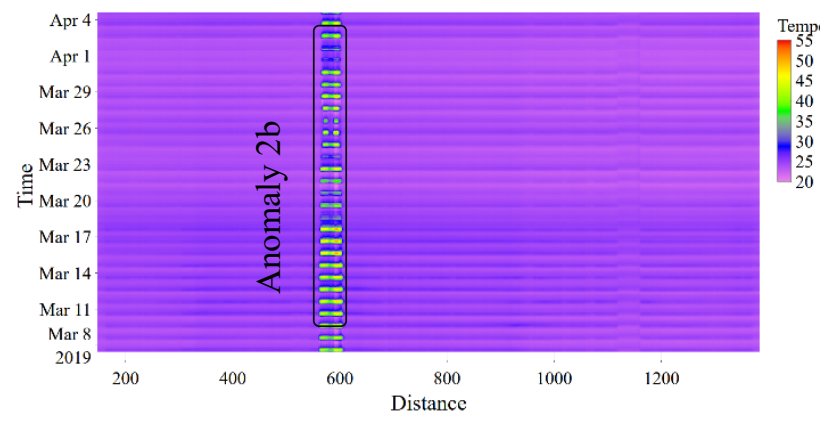

Figure 14. FO DTS Layout 2 - campaign 2

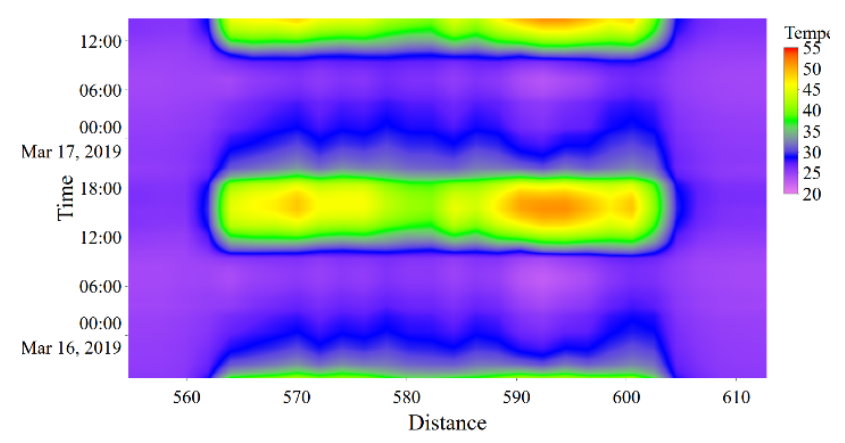

Figure 15. Detail of the $2 b$ anomaly

\subsubsection{Campaign 3}

Despite the fact that campaign 3 recorded the water level decrease on both layouts (see data from Layout 2 in Figure 16), no additional significant findings were made during this campaign.

\subsubsection{PS Spain conclusion}

For interpretation purposes, the heatmaps from PS Spain have been georeferenced to relevant embankments of the irrigation pond (Figure 17 and Figure 18). Except for the anomalies described in the chapters above, 2 other

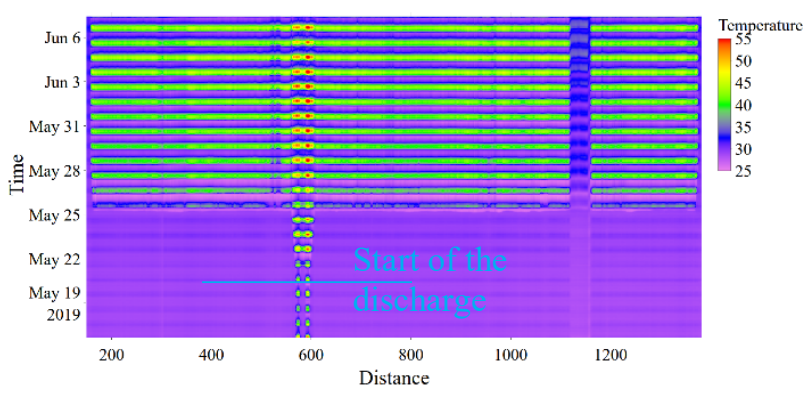

Figure 16. FO DTS Layout 2 - campaign 3

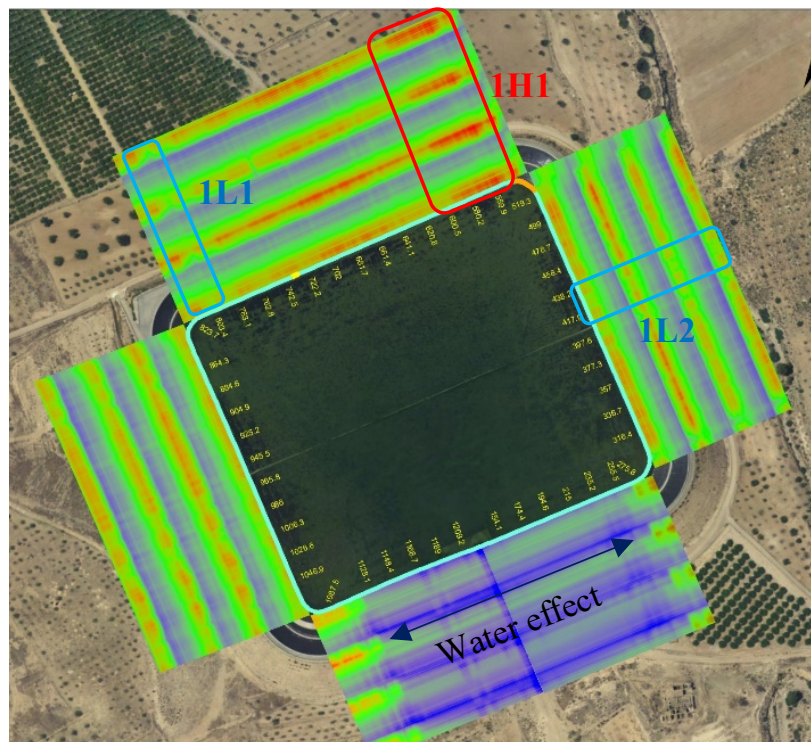

Figure 17. FO DTS Layout 1 georeferenced to the pond banks

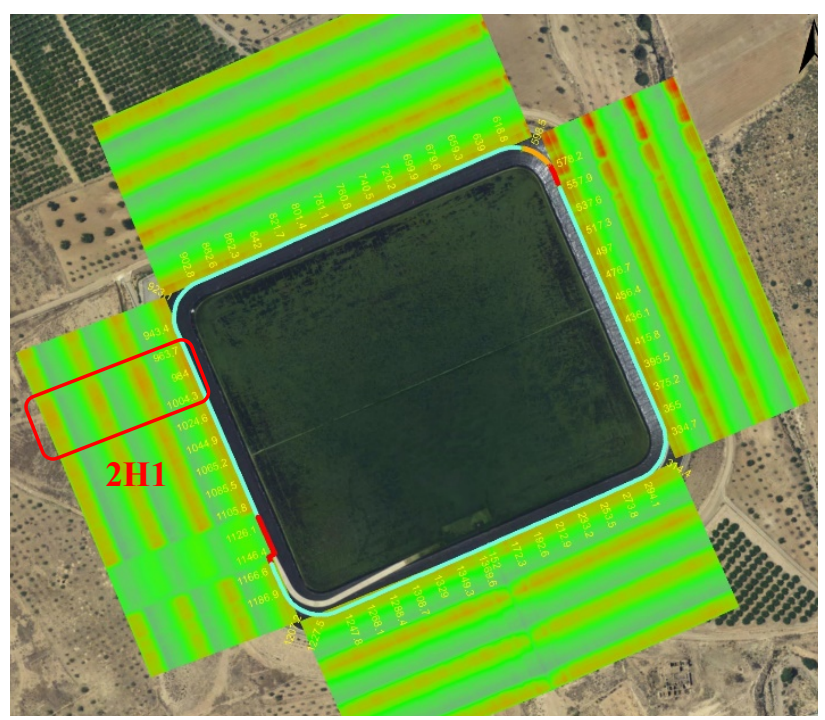

Figure 18. FO DTS Layout 2 georeferenced to the pond banks

types of anomalous sections have been identified. Sections $1 \mathrm{H} 1$ and $2 \mathrm{H} 1$ show higher amplitude of the diurnal temperature cycle. These higher-than-average thermal flux anomalies seem to spatially match the anomalies caused by the material with higher apparent resistivity measured by Slingram (anomalies W9 and W19 in Figure 19). In comparison with this, sections IL1 and IL2 show lowerthan-average heat flux and these spatially match some of 


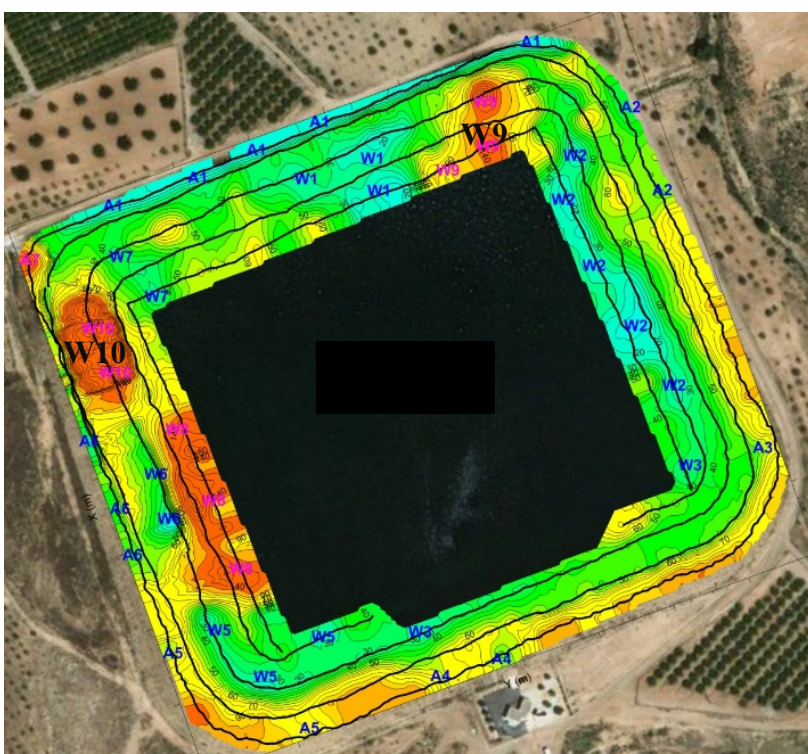

Figure 19. Contour map of the apparent resistivity measured by Slingram

the lower apparent resistivity areas measured by Slingram (W2, W7).

This correlation between temperature and resistivity anomalies can also be clearly seen between the profiles. For example, anomaly 1L2 manifests itself both in temperatures and resistivity values only at the waterside toe, whereas anomaly $2 \mathrm{H} 1$ manifests itself only at the berm.

Generally speaking, the comparison of resistivity (geophysical) data with temperature anomalies helps to correctly interpret possible seepage flows. Some temperature anomalies are caused by changes in embankment materials, or by the presence of "artificial" features with anomalous temperature properties.

The analysis of measured data further shows that the FO DTS profiles are located at a very shallow depth, or rather directly below the HDPE insulation foil. Considering the primary purpose of the FO DTS system installation, which is seepage detection, this arrangement appears entirely unsuitable, as the measurement FO cable would reach virtually the same temperature as water, separated from the cable only by a thin foil layer. In case of seepage, no anomalous temperature behaviour can be detected at the measurement profile to be identified and evaluated by the warning system.

\subsection{PS Hungary - Coal power plant ash pond}

From 12.12.2019 until 30.6.2020, the FO DTS reading unit collected temperature data along the measurement and reference profiles every hour. The length of one measurement was set at 300 seconds to optimise the signalto-noise ratio. The lengthwise resolution of the measurement was $2.02 \mathrm{~m}$, i.e. the reading unit returned an average temperature every $2.02 \mathrm{~m}$ section along the FO cable. Taking into account the length of the measurement and reference profiles and the measurement interval, the reading unit collected almost 800,000 valid temperature records for each profile.
The data have been processed and visualised in MS Excel and in python by the plotly library to create heatmap contour temperature charts providing clear spatiotemporal dependencies.

\subsubsection{Data evaluation}

Common temperature fluctuations at $\mathrm{M}$ and $\mathrm{R}$ profiles can be seen in Figure 20, with 2 selected measurements from the winter and summer season $\left(28^{\text {th }}\right.$ January and $28^{\text {th }}$ June 2020). It is evident that the amplitude of local temperature changes is much bigger at profile $M$ than at profile $\mathrm{R}$ (compare the $\mathrm{R}^{2}$ values of the linear trend for both profiles), which, we assume, is due to the water flow dynamics at profile $\mathrm{M}$. The anomalies indicating the presence of seepage are interpreted and highlighted with arrows in Figure 21. This graph displays the data from the measurement profile on two selected days of the winter and summer season (the same dates as in Figure 20). The two charts are merged using two independent $\mathrm{Y}$-axes for better visualisation of the relative warming and cooling effect of the seeping water in the winter and summer season, respectively.

The overview of temperature changes at the site in the monitored period is given in Figure 22 (profile $\mathrm{M}$ ) and Figure 23 (profile R). These are temperature heatmaps with a horizontal axis showing cable chainage values (profile chainage 0 to M 337 and R 322 according to Figure 8) and a vertical axis indicating time (December

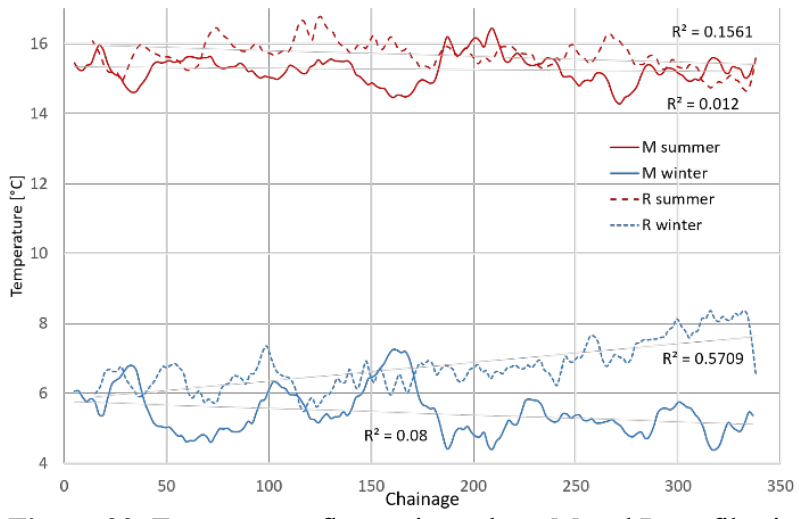

Figure 20. Temperature fluctuations along $M$ and $R$ profiles in winter and summer period

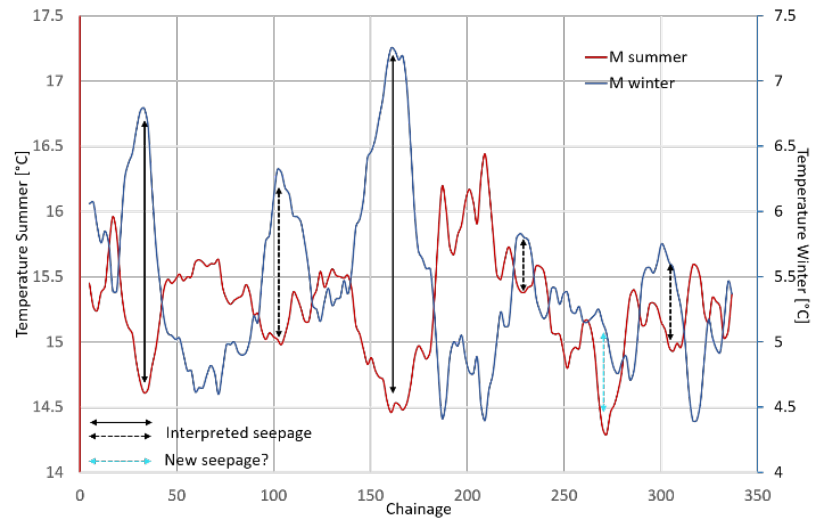

Figure 21. Temperature fluctuations along $M$ profile in winter and summer period with identified seepages 
2019 to June 2020). The colours indicate temperature at a particular profile area and time according to the given colour range.

According to our interpretation, local warming of the relatively cold dam body by seeping water takes place in seepage zones in the winter period, while in the summer seeping water cools down the relatively warm dam body. The relation between water temperature in the dam body (see temperature data in the borehole) and air temperature is shown on the graph in Figure 24. In the winter, seepage flows thus manifest themselves as local temperature maxima as opposed to local minima in the summer period. There is a period in the spring and autumn, however, when seeping water and the body of the dam at a particular depth have equal temperatures (temperature shift), so that the seepage cannot be identified based on temperatures. This period is highlighted in red and corresponds to a temperature of around $10{ }^{\circ} \mathrm{C}$. At PS Hungary, two significant seepage zones have been identified (around chainage 30 and 160) as well as three less significant anomalies (around chainage values 100, 230, and 300). An interesting anomaly is located at chainage 280, appearing only in the summer season. This may be a considerably shaded area. However, it cannot be ruled out that it indicates formation of a new seepage zone. We assume that the relative amplitude of the anomalies in contrast to surrounding areas corresponds to seepage intensity. For this reason, we assess the anomaly at chainage 160 as being the most intense seepage flow.

The situation at profile $\mathrm{R}$ is shown in Figure 23. There, uneven compaction of backfill materials likely took place (more details in 3.2.2), or the temperature fluctuations are due another factor (such as shading). In any case, temperature variations (dents) appear in the data within the

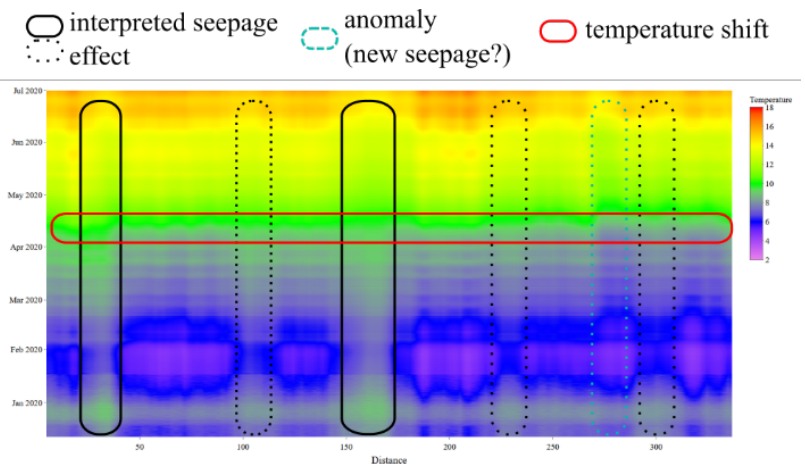

Figure 22. Heatmap of the M profile

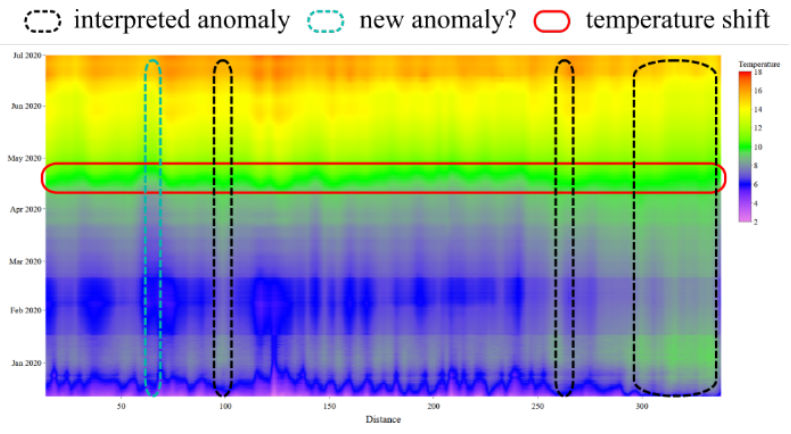

Figure 23. Heatmap of the R profile

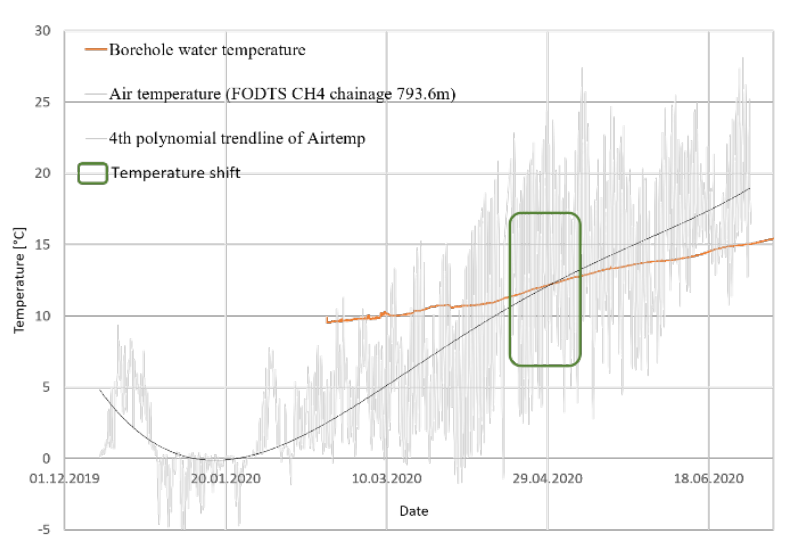

Figure 24. Air (dam surface) temperature and water temperature in observation borehole

first months with an amplitude of about 1.5 degrees and with section lengths of about $4 \mathrm{~m}$. Their intensity diminishes with time and in the summer period, the dents are almost imperceptible. This obviously reduces the usefulness of profile $\mathrm{R}$ for checking the interpretation of anomalies at profile M. Also, indications of similar type of anomaly were recorded at profile $\mathrm{R}$, which at profile $\mathrm{M}$ are interpreted as manifestations of seeping water. This, however, appears unlikely due to the location of profile R. It must be also noted that the amplitude of these anomalies is about half as big as of those at profile $\mathrm{M}$, and it is therefore more likely due to shading of the profile.

\subsubsection{Backfilling effects}

The backfilling effects significantly differ at the reference and measurement profiles due to the difference in the quality of materials.

The reference profile consists of an ashy side product of the power plant which has been piled and compacted for decades. During trenching it turned out that not only simple compaction but cementation has occurred as well, and large, cemented blocks were dug out. After laying the cable, these blocks strongly affected the compaction process during and after backfilling.

The material of the measurement profile was homogeneous middle-grained sand without any sign of cementation. As a result, backfilling was done more evenly than in the reference profile.

These basic differences can be easily seen on the lower parts of the heat maps (Figure 22 and Figure 23). Before backfilling of profile $\mathrm{R}$, the cable was pressed down with small piles of ash to keep it in the middle of the trench. These piles were made at equal distances from each other and brought about local heat anomalies before and right after the backfilling of the trench was completed. These anomalies then disappeared during the heat compensation process within the whole profile $\mathrm{R}$, as can be seen in Figure 25 and Figure 26.

Some minor differences concerning the final compaction can also be seen in Figure 26. For instance, a double temperature peak starts to rise at section $940 \mathrm{~m}$ after the long-lasting $6-8{ }^{\circ} \mathrm{C}$ period which can be linked to uneven thermal insulation. 


\subsubsection{PS Hungary conclusion}

The results of temperature measurements at the Hungarian pilot site can be generally evaluated in the following way:

At the site, evaluation of temperature changes in the period December 2019 - June 2020 was carried out.

As it turned out, anomalies typical for water seeping through the dam body appear at profile $M$. These are sections where relative warming in the winter and, on the other hand, relative cooling in the summer takes place. This is due to the fact that the temperature in the dam to the depth where the optical fibre is placed (that is up to approx. $1.2 \mathrm{~m}$ ) is strongly affected by climatic conditions, that is air temperature. Temperature-wise, seeping water behaves neutrally, so that it warms up the dam body in winter and cools it down in summer. Thus, seeping water smooths out temperature data. This is clearly shown in Figure 27 where temperature fluctuations in time at selected points of profile $M$ are given. We can see temperature changes in a seepage area (red line) and further two areas without seepage (grey and orange) with varying degrees of air temperature effect (probably depending on thermal conductivity of the backfill). It is obvious that the half-yearly temperature variations in a seepage area are considerably smaller $\left(7^{\circ} \mathrm{C}\right)$ than those outside seepage zones (up to $12{ }^{\circ} \mathrm{C}$ ). What also becomes apparent is the period when seepage flows cannot be analysed based on temperature (red rectangle $10^{\text {th }}-30^{\text {th }}$ April 2020).

Relative amplitude of temperature change in a seepage area in contrast to its surroundings (increased temperature in winter, temperature decrease in summer) probably corresponds to seepage intensity. From this perspective, the most significant seepage zone along profile $\mathrm{M}$ appears to be the area around profile chainage 160 and 30 . Three less significant anomalies were recorded around chainage values 100,230 , and 300 . The situation of the interpreted seepage flows is drawn in Figure 28. What is interesting is that seepage flows according to FO DTS are bound to the edges of the interpreted seepage zones according to geophysics, and that they occur along the elongation of the outfall of the carrier pipe into the sludge pond. Assuming that the piping runs through the dam body along the fall line down to the dam toe, the link between risk-posing anomalies and the piping is evident. For detailed interpretation, precise route of the piping through the dam and the depth at which it is placed need to be known. In any case, the inhomogeneity running across the dam could be a preferential seepage pathway. In addition to that, the effect of the piping on temperature changes within the dam cannot be ruled out, providing that the piping is located in the vicinity of the optical cable.

\section{Perspectives of automatic seepage evaluation based on FO DTS data}

As it turned out, FO DTS along with preliminary geophysical survey is highly capable of detecting underground seepages in dam bodies. The position of seepages can be precisely identified, so that further

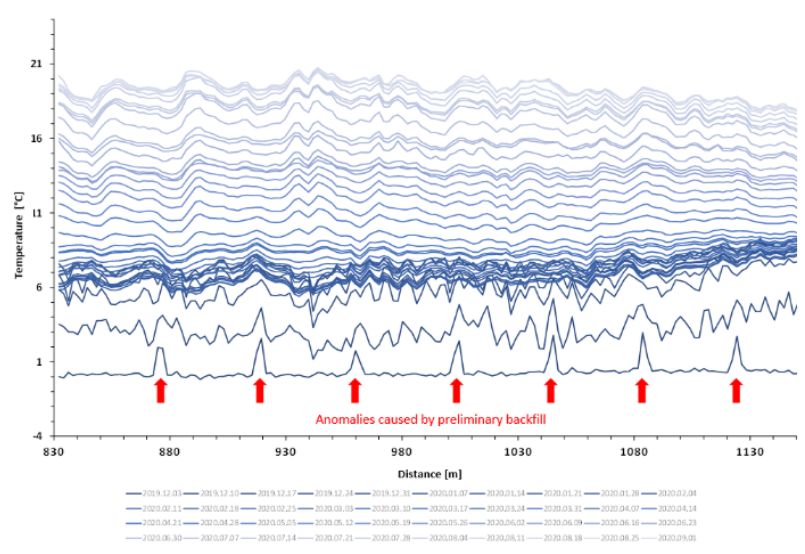

Figure 25. Weekly temperature profiles of R profile

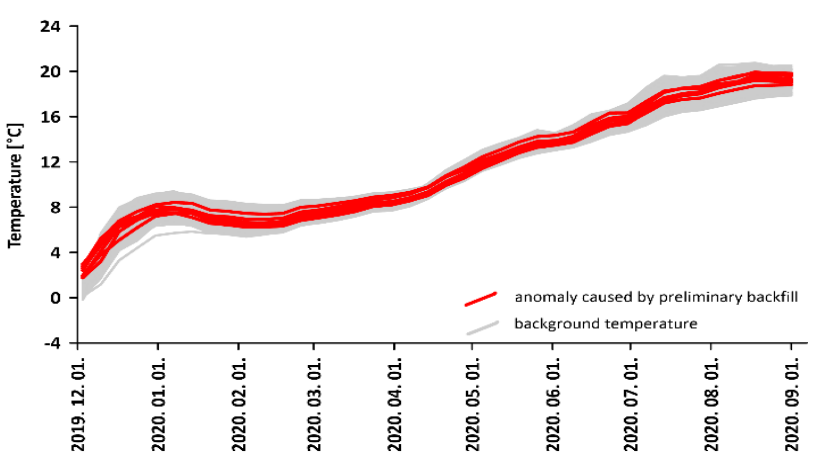

Figure 26. Timeline view of some sections of R profile

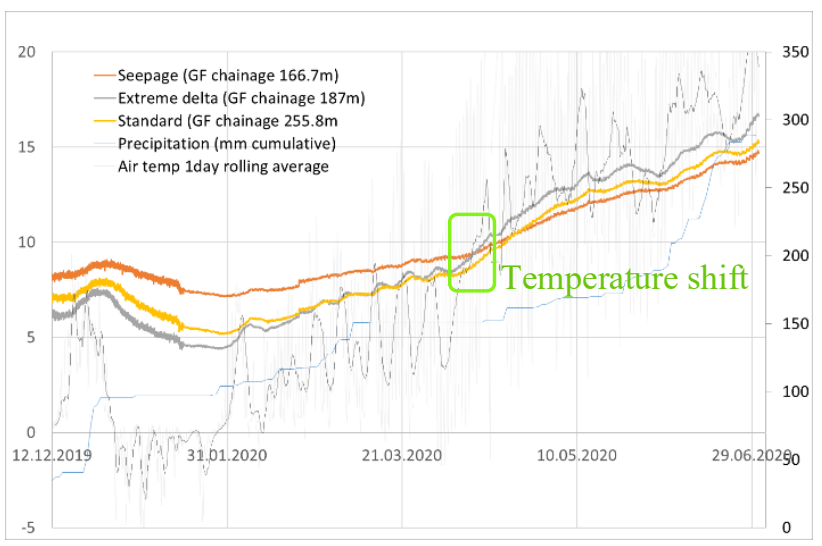

Figure 27. Temperature trends at different FO DTS sections

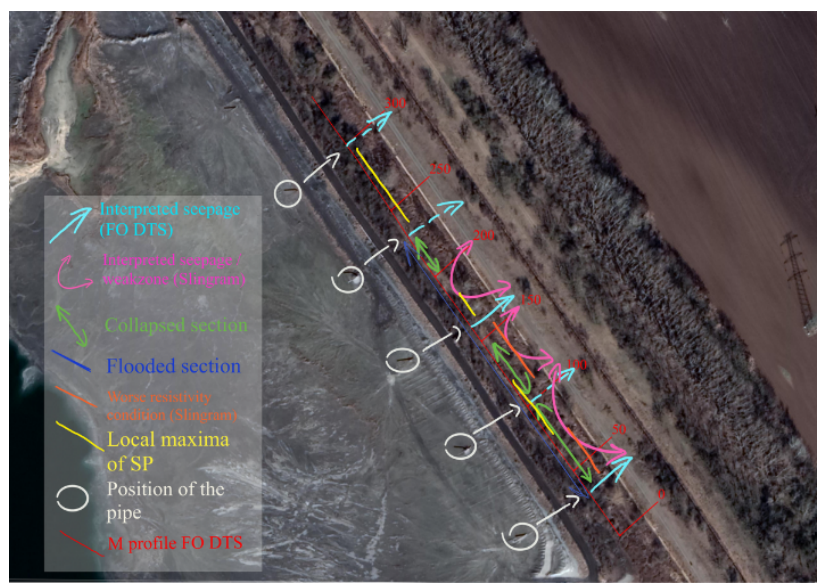

Figure 28. Interpretation of the GF and FO DTS results 
geotechnical interventions can be planned if necessary. Complex evaluation of a great amount of data enhances safe operation of dam systems.

With an automatized evaluation system, this safety process can be made more effective. This means that not only raw data files are available, but the mass of data is also processed and organized with the possibility of creating various types of charts and statements.

Furthermore, with reliable distinguishable types of anomalies and quantifiable evaluation, an automatic alarm system can be set up, increasing the efficiency of the monitoring system.

Based on data evaluated on both pilot sites, two methods appear to be promising for the identification of the FO DTS sections affected by seepage.

The first method could be based upon the relative "flatness" of the temperature trend over time at the sections affected by seepage compared to the "dry" sections, as can be clearly seen in Figure 27. By applying the discrete differential calculus, the temperature trends of sections affected by seepage compared to "dry" sections should show a dependence according to the equation (1).

$$
\left(\sum_{i=0}^{n}\left|\frac{\Delta t_{i}}{\Delta \tau_{i}}\right|\right)_{s e e p}<\left(\sum_{i=0}^{n}\left|\frac{\Delta t_{i}}{\Delta \tau_{i}}\right|\right)_{d r y}
$$

$\begin{array}{ll}\Delta \mathrm{t}_{\mathrm{i}}=\mathrm{t}_{\mathrm{i}+1}-\mathrm{t}_{\mathrm{i}} & \text { temperature increment } \\ \Delta \mathrm{t}_{\mathrm{i}}=\mathrm{t}_{\mathrm{i}+1}-\mathrm{t}_{\mathrm{i}} & \text { chosen time interval } \\ \text { seep } & \text { FO DTS section affected by seepage } \\ \text { dry } & \text { FO DTS section unaffected by seepage }\end{array}$

If choosing the right time interval and sufficient time series, this method might filter out the "suspicious" sections during the calibration of the FO DTS system.

The second method, which might be successfully used for the identification of seepage zones while including air temperature, water temperature and water level data, is principal component analysis. However, the description of this approach exceeds the scope of this paper and will not be further discussed.

\section{Discussion and conclusion}

The experience made during project FORMTES pilot measurements has confirmed the validity of the STAMFOR methodology. Successful deployment of the FO DTS technology for seepage detection requires several preconditions:

- Each site (dam) requires individual approach. The system needs to be adjusted to the particular dam construction features as well as to the requirements for coverage of risk-posing areas (such as covering the reservoir bottom, waterside or landside toe of the dam).

- It is necessary to gather maximum information on the site's geological structure and the structure of the dam, e. $\mathrm{g}$. from construction documents.

- Real condition of the dam (reservoir) needs to be determined using first geophysical methods (such as the GMS method). Material composition of the dam and saturation of the dam with water are monitored, and seepage flows are tentatively located. Next step is direct survey of selected areas through boreholes and pits.

- Finally, probable seepage regime of the dam needs to be understood. Using all the above mentioned information, seepage model of the dam body is created, which is a basis for an appropriate design of FO DTS profile location as well as for choosing the right depth for the cables to be placed.

Experience has shown that the system cannot properly work to prevent breakdowns unless the abovementioned pattern is followed. An example may be the site in Spain where the cables did not cover risk-posing areas (reservoir bottom or drainage system) and, at the same time, they had been placed at a too shallow depth on the waterside slope. As a result, the effect of water temperature in the reservoir and seepage flows cannot be distinguished from each other.

On the other hand, the FO DTS system implementation in Hungary shows early detection of risk-posing seepage flows. Relative seepage intensity may be interpreted. The location of the seepage flows indicates possible relation between seepage and a carrier pipe, which poses a risk of piping.

We expect that automatic evaluation of the measured temperature data will take place in the future, as mentioned in Chapter 4. However, the FO DTS system will always need to be individually fine-tuned for each site and the parameters of the automatic data evaluation system will need to be properly set.

\section{References}

1. Balisa, B., T. Bartynski, R. Brzoza-Woch, M. Bubak, D. Harezlak and M. Kasztelnik (2016). Dedicated IT infrastructure for Smart Levee Monitoring and Flood Decision Support. FLOODrisk 2016 - 3rd European Conference on Flood Risk Management, Lyon, E3S Web of Conferences.

2. Boukalová, Z. and V. Beneš (2007). Dike breaks prevention as the process of flooding protection. Proceedings of the IAHR Congress. Venice.

3. Boukalová, Z., V. Beneš, F. Čejka and T. Hájek (2010). Practical use of Geophysical monitoring system (GMS) focussed on WP3 activities. Prague: FloodProBE.

4. Čejka, F., V. Beneš, F. Glac and Z. Boukalová (2018). Monitoring of Seepages in Earthen Dams and Levees. International Journal of Environmental Impacts, Vol. 1, Issue 3, pp. 267278.

5. Dwornik, M., K. Krawiec, A. Franczyk and A. Leśniak. (2016). Numerical modelling of levee stability based on coupled mechanical, thermal and hydrogeological processes. FLOODrisk 2016 - 3rd European Conference on Flood Risk Management. Lyon, E3S Web of Conferences.

6. Khan, A. A., V. Vrabie, J. I. Mars, A. Girard and G. D’Urso. (2010). Automatic Monitoring System for Singularity Detection in Dikes By DTS Data Measurement. IEEE Transactions on 
Instrumentation and Measurement, 59(8): 21672175.

7. Normandale, D. (2016). Assessing flood defence integrity using geophysical monitoring techniques. ADA Gazette Winter 2016, p. 19.

8. Pyayt, A., A. Kozionov, I. Mokhov, B. Lang, R. Meijer, V. Krzhizhanovskaya and P. Sloot. (2014). Time-Frequency Methods for Structural Health Monitoring. Sensors, 14(3): 5147-5173.

9. Schenato, L. (2017). A Review of Distributed Fibre Optic Sensors for Geo-Hydrological Applications. Applied Sciences 7(9), 896.

10. SMARTEC. (16. 12. 2018). https://smartec.ch. Downloaded from Smartec SA webpage.

11. Su, H. and Y. Kang. (2013). Design of System for Monitoring Seepage of Levee Engineering Based on Distributed Optical Fiber Sensing Technology. International Journal of Distributed Sensor Networks 9(12). 